\title{
Palladium-Catalyzed Asymmetric Hydrosilylation of Cyclohexa-1,3-diene with Trichlorosilane by Use of Chiral Phosphoramidite Ligands from 3,3'-Disubstituted 1,1'-Binaphthols
}

\author{
Hyun-Sub Park, Hye Mi Shin, Suk Namgung, and Jin Wook Han* \\ Department of Chemistry, College of Natural Sciences, Institute of Nanoscience and Technology, Hanyang University, \\ Seoul 133-791, Korea. ${ }^{*}$-mail: jwhan@hanyang.ac.kr \\ Received May 1, 2014, Accepted May 20, 2014
}

Key Words : Asymmetric catalysis, Hydrosilylation, Palladium, Chiral phosphoramidites, Allylsilane

Since a breakthrough enhancing catalytic activity and enantioselectivity by use of axially chiral monophosphine ligands (MOP) was reported in the hydrosilylation of 1octene, ${ }^{1 \mathrm{a}}$ the substrate scope has been broadened to terminal alkenes, cyclic alkenes, $\beta$-substituted styrenes, conjugated 1,3-dienes, and 1,3-enynes by use of the MOP family. ${ }^{1}$ Of those MOP ligands, $(R)$-Ar-MOP (L1) and its derivative $(R)$ L2 are the most enantioselective ligands for cyclic 1,3dienes (Figure 1). ${ }^{2}$ Meanwhile, chiral monodentate phosphorus ligands, such as phosphoramidite ligands, planar chiral ligands, and helically chiral phosphine ligands have been reported to induce excellent enantioselectivities and catalytic activities in the hydrosilylation of styrenes. ${ }^{3-5}$ However, only a few examples related to asymmetric hydrosilylation of olefins other than styrenes with those monodentate phosphorus ligands have appeared in the literatures. ${ }^{6}$ Recently, we reported asymmetric hydrosilylation of cyclohexa-1,3-diene using chiral phosphoramidite ligands including a sterically demanding phosphoramidite $(S)$-L3 (Figure $1)^{6 \mathrm{~b}}$ It has been found from our previous study that the enantioselectivities varied dramatically depending on the ligands applied and the highest enantioselectivity of $87 \%$ ee ever observed for the substrate has been achieved by use of (S)-L3.

Herein, we wish to report as an extension of our studies that asymmetric hydrosilylation of cyclohexa-1,3-diene (1) with trichlorosilane in the presence of palladium catalysts coordinated with chiral phosphoramidite ligands (L4) prepared from 3,3'-disubstituted $(S)$-1,1'-binaphthols and secondary amines ${ }^{7}$ were examined in order to evaluate the influence of binaphthyl part of the phosphoramidite ligands in both catalytic activity and enantioselectivity (Scheme 1). Thus, the hydrosilylation was carried out without solvent in

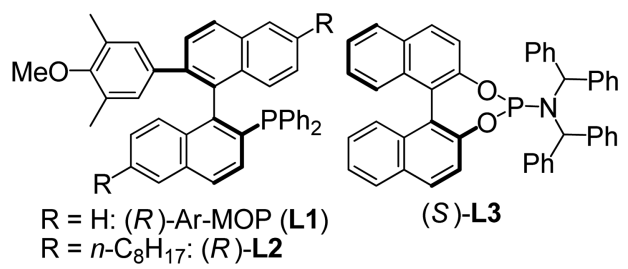

Figure 1 the presence of $1.0 \mathrm{~mol} \%$ of palladium catalysts generated in situ by mixing $\left[\mathrm{PdCl}\left(\pi-\mathrm{C}_{3} \mathrm{H}_{5}\right)\right]_{2}$ and chiral phosphoramidites $\mathbf{L} 4(\mathrm{Pd} / \mathrm{P}=1 / 2)$. The reactions proceeded smoothly at $20{ }^{\circ} \mathrm{C}$ in $20 \mathrm{~h}$ to give $(R)-3$-(trichlorosilyl)cyclohexene (2) in high yields and the resulting allyl(trichloro)silane $\mathbf{2}$ was subsequently reacted with benzaldehyde in DMF to produce (3S,1'R)-3-[hydroxyl(phenyl)methyl]cyclohexene (3), which was subjected to HPLC analyses with a chiral stationary phase column for the determination of enantioselectivities. The catalytic activity by the present catalytic system with $\mathbf{L 4}$ was also high when compared with the hydrosilylation of the substrate by use of Ar-MOP (L1) ${ }^{2 \mathrm{a}}$ and the phosphoramidites from unmodified binaphthol. ${ }^{6 \mathrm{~b}}$ However, the enantioselectivity varied between $23 \%$ ee and $65 \%$ ee at $20{ }^{\circ} \mathrm{C}$ according to the ligands applied. From the results summarized in Table 1 and our previous report, it was revealed that enantioselectivities were dependent on the substituents at 3,3'-positions of the binaphthyl part. Overall, the ligands having phenyl substituents at 3,3'-positions induced higher enantioselectivities than others. Thus, the enantioselectivities with L4a and L4c were higher than L4f and L4g, respectively (entries 1, 3, 7, and 8). In case of the ligands $\mathbf{L 4 b}$ and L4c having 3,3'-diphenylbinaphthyl part also showed higher selectivities than the corresponding ligands having unmodified binaphthyl part (entries 2 and 3 ). ${ }^{6}$ It was also found that the reactions with $\mathbf{L} \mathbf{4 d}$ gave an unsatisfactory result in both catalytic activity and enantioselectivity (entry 5). On the other hand, methyl substituents at 3,3'-positions were not beneficial on the enantioselectivity but catalytic activities were high enough. For example, the dimethyl groups on binaphthyl part in ligands $(S, R, R)$-L4h and $(S, S, S)$-L4i had detrimental effects on enantioselectivity, giving lower enantiomeric excesses than the corresponding ones having unmodified binaphthyl part (entries 9 and 10). ${ }^{6 \mathrm{~b}}$ It is shown in this study that the ligands combined 3,3'-diphenylbinaphthyl with di(isopropyl)amino or dibenzylamino part showed the highest selectivities among the ligands examined (entries 1 and 3).

The highest enantioselectivity of $72 \%$ ee was achieved with $\mathbf{L} \mathbf{4 c}$ by lowering the reaction temperature (entry 4).

In summary, chiral phosphoramidite ligands (L4) prepared from 3,3'-disubstituted $(S)$-1,1'-binaphthols is applied in 

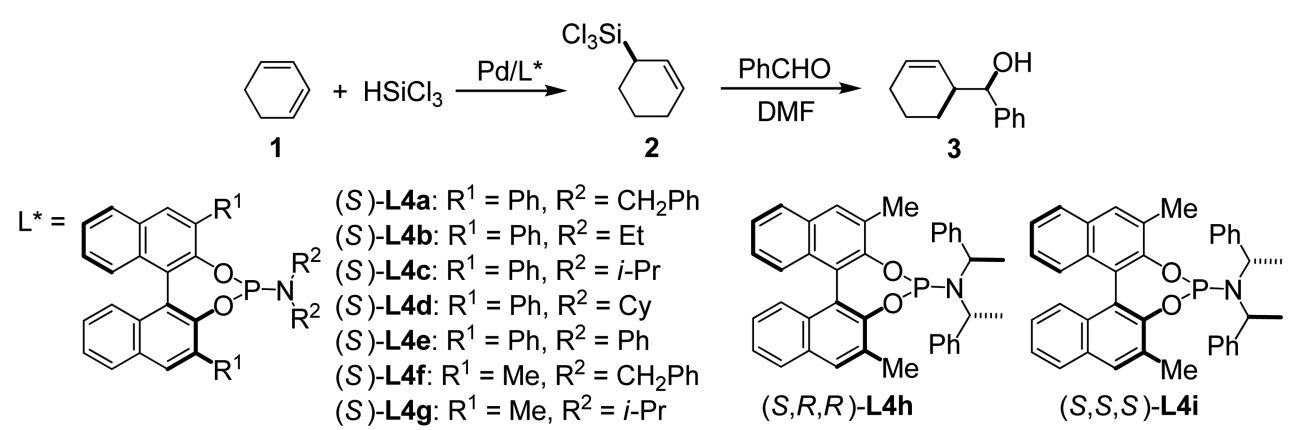

Scheme 1. Pd-catalyzed asymmetric hydrosilylation of cyclohexa-1,3-diene using chiral phosphoramidites L4.

Table 1. The hydrosilylation of cyclohexa-1,3-diene ${ }^{a}$

\begin{tabular}{|c|c|c|c|c|c|}
\hline Entry & $\mathrm{L}^{*}$ & $\begin{array}{l}\text { Time } \\
\text { (h) }\end{array}$ & $\begin{array}{l}\text { Temp } \\
\left({ }^{\circ} \mathrm{C}\right)\end{array}$ & $\begin{array}{c}\text { Yield }^{b} \\
(\%)\end{array}$ & $\% \mathrm{ee}^{c}$ \\
\hline 1 & $(S)-\mathbf{L} \mathbf{4 a}$ & 20 & 20 & 97 & $64(R)$ \\
\hline 2 & $(S)-\mathbf{L} 4 \mathbf{b}$ & 20 & 20 & 88 & $45(R)$ \\
\hline 3 & $(S)-\mathbf{L} \mathbf{4 c}$ & 20 & 20 & 90 & $65(R)$ \\
\hline 4 & $(S)-\mathbf{L} \mathbf{4 c}$ & 72 & -10 & 61 & $72(R)$ \\
\hline 5 & $(S)-\mathbf{L} 4 \mathbf{d}$ & 20 & 20 & 53 & $37(R)$ \\
\hline 6 & $(S)-\mathbf{L} 4 \mathbf{e}$ & 20 & 20 & 96 & $23(R)$ \\
\hline 7 & $(S)-\mathbf{L} \mathbf{4 f}$ & 20 & 20 & 99 & $53(R)$ \\
\hline 8 & $(S)-\mathbf{L} \mathbf{4 g}$ & 20 & 20 & 99 & $37(R)$ \\
\hline 9 & $(S, R, R)-\mathbf{L} \mathbf{4 h}$ & 20 & 20 & 99 & $33(R)$ \\
\hline 10 & $(S, S, S)-\mathbf{L} \mathbf{4 i}$ & 20 & 20 & 52 & $31(R)$ \\
\hline
\end{tabular}

${ }^{a}$ The reaction was performed with $2 \mathrm{mmol}$ of $\mathbf{1}$. The initial ratio of $\mathbf{1} /$ $\mathrm{HSiCl}_{3} / \mathrm{Pd} / \mathrm{L}^{*}$ was $1.0 / 1.2 / 0.010 / 0.020 .{ }^{b}$ Isolated yield of 2 by bulb-tobulb distillation. ${ }^{c}$ Determined by HPLC analyses of $\mathbf{3}$ with a chiral stationary column (Daicel Chiralpak OB-H).

palladium-catalyzed asymmetric hydrosilylation of cyclohexa-1,3-diene with trichlorosilane to show that diphenyl substituents at 3,3'-positions of the binaphthyl induced higher enantioselectivity. Our efforts to expand the substrate scope of the hydrosilylation by use of various monodentate phosphorus ligands are on progress.

Acknowledgments. This work was supported by National Research Foundation of Korea Grant funded by the Korean Government (2011-0010550) and by Basic Science Research
Program (2012R1A6A1029029).

\section{References}

1. (a) Uozumi, Y.; Hayashi, T. J. Am. Chem. Soc. 1991, 113, 9887. (b) Hayashi, T. Acta Chem. Scand. 1996, 50, 259. (c) Hayashi, T. Acc. Chem. Res. 2000, 33, 354. (d) Hayashi, T.; Hirate, S.; Kitayama, K.; Tsuji, H.; Torii, A.; Uozumi, Y. J. Org. Chem. 2001, 66, 1441. (e) Shimada, T.; Mukaide, K.; Shinohara, A.; Han, J. W.; Hayashi, T. J. Am. Chem. Soc. 2002, 124, 1584. (f) Han, J. W.; Tokunaga, N.; Hayashi, T. J. Am. Chem. Soc. 2001, 123, 12915.

2. (a) Hayashi, T.; Han, J. W.; Takeda, A.; Tang, J.; Nohmi, K.; Mukaide, K.; Tsuji, H.; Uozumi, Y. Adv. Synth. Catal. 2001, 343, 279. (b) Han, J. W.; Hayashi, T. Chem. Lett. 2001, 976. (c) Han, J. W.; Hayashi, T. Tetrahedron Asymmetry 2002, 13, 325. (d) Han, J. W.; Hayashi, T. Tetrahedron Asymmetry 2010, 21, 2193.

3. For chiral phosphoramidite ligands: (a) Jensen, J. F.; Svendsen, B. Y.; la Cour, T. V.; Pedersen, H. L.; Johannsen, M. J. Am. Chem. Soc. 2002, 124, 4558. (b) Zhang, F.; Fan, Q.-H. Org. Biomol. Chem. 2009, 7, 4470. (c) Ficks, A.; Hiney, R. M.; Harrington, R. W.; Gilheany, D. G.; Higham, L. J. Dalton Trans. 2012, 41, 3515.

4. For planar chiral ligands: (a) Hayashi, T.; Tamao, K.; Katsuro, Y.; Nakae, I.; Kumada, M. Tetrahedron Lett. 1980, 21, 1871. (b) Pedersen, H. L.; Johannsen, M. Chem. Commun. 1999, 2517. (c) Pedersen, H. L.; Johannsen, M. J. Org. Chem. 2002, 67, 7982.

5. For helically chiral ligands: (a) Yamomoto, T.; Suginome, M. Angew. Chem. Int. Ed. 2009, 48, 539. (b) Yamomoto, T.; Yamada, T.; Nagata, Y.; Suginome, M. J. Am. Chem. Soc. 2010, 132, 7899.

6. (a) Ogasawara, M.; Ito, A.; Yoshida, K.; Hayashi, T. Organometallics 2006, 25, 2715. (b) Park, H. S.; Han, J. W.; Shintani, R.; Hayashi, T. Tetrahedron Asymmetry 2013, 24, 418.

7. Park, H.-S.; Namgung, S.; Shin, H. M.; Ahn, H. J.; Han, J. W. Bull. Korean Chem. Soc. 2014, 35, 2243. 